\title{
ИНВЕСТИЦИОННОЕ ПРОГНОЗИРОВАНИЕ ЦЕЛЕВОГО РАЗВИТИЯ КОНКУРЕНТОСПОСОБНОСТИ ЧЕЛОВЕЧЕСКОГО КАПИТАЛА
}

\author{
(C) 2021 Герасимова Светлана Витальевна \\ кандидат экономических наук, доцент \\ Московский государственный медико-стоматологический университет \\ им. А. И. Евдокимова, Россия, Москва \\ E-mail: lanapost@inbox.ru
}

В статье рассмотрена проблема эффективного инвестиционно-целевого развития конкурентоспособности человеческого капитала. Предложена модель агрегированной оценки качества человеческого капитала. Приведена инвестиционная модель прогнозирования развития стратегической конкурентоспособности человеческого капитала на примере медицинской организации, изложен иллюстративный пример.

Ключевые слова: конкурентоспособность, модель, качество, инвестиции, целевое развитие, стратегическая конкурентоспособность, человеческий капитал, медицинские услуга.

В статье рассмотрена инвестиционная модель прогнозирования развития долгосрочных конкурентных преимуществ человеческого капитала на примере медицинской организации, применяемая в ситуации неконкурентоспособности ее факторов производства. Ключевой характеристикой развития человеческого капитала принят относительный уровень его качества с учетом особенностей рынка труда медицинских организаций. Рассмотрена агрегированная модель целевого инвестирования в развитие человеческого капитала для обеспечения его стратегической конкурентоспособности на рынке факторов производства. Приведен иллюстративный пример конкретной целевой инвестиционной программы нормативного прогнозирования развития человеческого капитала, имеющей «параллельную» структуру. Выбранная структура обеспечивает максимальную оперативность в обеспечении долгосрочной конкурентоспособности персонала медицинской организации. Проведен анализ решаемой задачи в условиях частичной и полной неопределенности реактивного поведения внешней среды, имеющей конкурентный характер. Рассмотрена матричная модель устранения перспективной неопределенности на основе критерия максимума среднего гарантированного уровня перспективной конкурентоспособности человеческого капитала.

Опережающее развитие конкурентоспособности человеческого капитала медицинских организаций представляет собой актуальную научно-практическую проблему, оно необходимо для обеспечения их стратегической эффективности на основе формирования долгосрочных конкурентных преимуществ. Решающая роль в решении этой задачи принадлежит стратегии сбалансированного развития факторов производства: овеществленного и человеческого капитала. Следует отметить, что развитие научно-технического прогресса в сфере медицинских технологий значительно опережает уровень развития человеческого капитала современных медицинских организаций. Стратегия синхронизации их развития является, на наш взгляд, первоочередной задачей обеспечения долговременной конкурентоспособности. Следует отметить, что к человеческому капиталу относится только квалифицированный, сложный труд, осуществляемый с применением новейших медицинских технологий. Спрос на такой труд предъявляют медицинские организации на рынке факторов производства. Это означает, что в состав потребительских характеристик человеческого капитала для медицинских организаций входят: профессионализм, квалификация, опыт работы, интеллект, уровень развития личности, здоровье, социально-психологические качества, уровень социализации. Показатель «уровень социализации» введен в связи с широким использованием в клиниках труда врачей-мигрантов, носителей иных социокультурных ценностей. Соблюдение ими социальных норм и правил нашей страны, как правило, осуществляется не полностью, что содержит потенциальную воз- 
можность возникновения общественных противоречий. Перечисленный состав потребительских характеристик человеческого капитала как товара на рынке труда позволяет сформировать модель «идеального» человеческого капитала в виде совокупности наиболее предпочтительных значений этих характеристик с позиции конкурентоспособности на рынке труда медицинских организаций. Для оценки конкретных значений потребительских характеристик (ПХ) может быть выбрана количественная, порядковая или лингвистическая шкала. Например, в наиболее распространенной, лингвистической пятиразрядной шкале: «отличный» (О), «высокий» (В), «средний (С), «удовлетворительный» (У), «неудовлетворительный» (Н) уровень ПХ - желаемые клиниками уровни потребительских характеристик врача и их относительная важность приведены в Табл. 1. В примере предполагается, что клиника оказывает медицинские услуги на сегменте класса «стандарт», где предъявляются примерно одинаковые требования к характеристикам стоимости услуг и их качества.

Для обобщенной оценки качества человеческого капитала следует нормировать коэффици- енты относительной важности, а лингвистические значения желаемого уровня ПХ перевести в пятибалльную шкалу.

Модель (1) обобщенной оценки «идеального» уровня качества человеческого капитала имеет вид:

$$
\left\{\begin{array}{l}
\mathrm{y}^{*}=\Sigma \mathrm{OBi} \cdot \mathrm{yi}^{*} \\
\Sigma \mathrm{OBi}=1
\end{array}\right.
$$

Модель фактического уровня качества человеческого капитала, как правило, не полностью соответствует требованиям рынка, а иногда уступает уровню человеческого капитала фирмы-конкурента. В этом случае необходима инвестиционная программа прогнозирования развития качества человеческого капитала до целевого уровня: превосходства над конкурентом. Агрегированными характеристиками такой программы являются: срок выполнения, траектория инвестиций, новый уровень потребительских характеристик человеческого капитала, оптимальные по установленным целевым критериям.

Таблица 1. Пример качественной модели «идеального человеческого капитала» для потребителей класса «стандарт»

\begin{tabular}{|c|l|c|c|}
\hline № & \multicolumn{1}{|c|}{ Потребительская характеристика } & $\begin{array}{c}\text { Относительная } \\
\text { важность }\end{array}$ & $\begin{array}{c}\text { Желаемый } \\
\text { уровень }\end{array}$ \\
\hline 1 & Профессиональные знания и квалификация & 0,7 & О \\
\hline 2 & Опыт работы & 0,4 & $\mathrm{C}$ \\
\hline 3 & Интеллект & 0,8 & $\mathrm{C}$ \\
\hline 4 & Качества личности & 0,6 & $\mathrm{~B}$ \\
\hline 5 & Здоровье & 0,8 & $\mathrm{C}$ \\
\hline 6 & Социально-психологические качества & 0,5 & $\mathrm{O}$ \\
\hline 7 & Уровень социализации & 0,9 & \\
\hline
\end{tabular}

Таблица 2. Обобщенная оценка качества «идеального» человеческого капитала

\begin{tabular}{|c|l|c|c|}
\hline \multicolumn{1}{|c|}{$\begin{array}{c}\text { Потребительская } \\
\text { арактеристика, ПХі }\end{array}$} & $\begin{array}{c}\text { Относительная } \\
\text { важность, ОВі }\end{array}$ & $\begin{array}{c}\text { Желаемый уровень } \\
\text { уі** }\end{array}$ \\
\hline 1 & Профессиональные знания и квалификация & 0.15 & 4 \\
\hline 2 & Опыт работы & 0.09 & 4 \\
\hline 3 & Интеллект & 0.17 & 3 \\
\hline 4 & Качества личности & 0.14 & 3 \\
\hline 5 & Здоровье & 0.17 & 5 \\
\hline 6 & Социально-психологические качества & 0.11 & 4 \\
\hline 7 & Уровень социализации & 0.19 & 4 (высокий) \\
\hline \multicolumn{2}{|c|}{ Обобщенный уровень «идеального» качества } \\
\hline
\end{tabular}


Рассмотрим иллюстративный пример, приведенный в Табл. 3.

Как видим, клиника исходно неконкурентоспособна по качеству человеческого капитала. Необходима целевая инвестиционная программа его развития в составе комплексной долгосрочной целевой программы развития медицинской организации.

В Табл. 4 приведены возможные инвестиционные мероприятия целевой программы.

Каждое из инвестиционных мероприятий имеет свою сумму расходов и срок выполнения. Вместе они образуют целевую программу повышения конкурентоспособности человеческого капитала.

Рассмотрим пример подобной целевой программы. В Табл. 5 приведены ее основные параметры; комплекс мероприятий, их взаимосвязь, срок проведения, финансовая потребность. Необходим прогноз результата развития конку- рентоспособности человеческого капитала. Целевая программа предполагает параллельное, независимое выполнение инвестиционных мероприятий. Срок такой программы определяется продолжительностью самого «долгого» мероприятия. Это - увеличение профессиональных знаний. Срок инвестиционной программы составил 1 год, то есть она является краткосрочной.

Как видим, функция прогноза интенсивности инвестиций целевой программы (ЦП) имеет ступенчатый вид, в соответствии с установленным календарным периодом. Она имеет существенную неравномерность. Максимальная интенсивность инвестиций имеет место в начальный период, в первые два месяца. Она составляет 2450 у.е./мес. Затем интенсивность потребности в инвестициях значительно сокращается в связи с завершением второго мероприятия и составляет 950 у.е./мес. Во второй половине года она еще раз сокращается в связи

Таблица 3. Исходная конкурентная ситуация.

\begin{tabular}{|c|l|c|c|c|c|}
\hline № & $\begin{array}{c}\text { Потребительская } \\
\text { характеристика, ПХі }\end{array}$ & $\begin{array}{c}\text { Относительная } \\
\text { важность, ОВі }\end{array}$ & Клиника & Конкурент & $\begin{array}{c}\text { Желаемый } \\
\text { уровень, уі* }\end{array}$ \\
\hline 1 & Проф. знания и квалификация & 0.15 & 4 & 5 & 5 \\
\hline 2 & Опыт работы & 0.09 & 3 & 2 & 4 \\
\hline 3 & Интеллект & 0.17 & 3 & 3 & 3 \\
\hline 4 & Качества личности & 0.14 & 4 & 3 & 3 \\
\hline 5 & Здоровье & 0.17 & 3 & 4 & 4 \\
\hline 6 & $\begin{array}{l}\text { Социально-сихологические } \\
\text { качества }\end{array}$ & 0.11 & 4 & 4 & 5 \\
\hline 7 & Уровень социализации & 0.19 & 3 & 3.46 & 3.74 \\
\hline
\end{tabular}

Таблица 4. Инвестиционные мероприятия по повышению конкурентоспособности

\begin{tabular}{|c|c|c|c|c|c|}
\hline № & $\begin{array}{c}\text { Потребительская } \\
\text { характеристика, ПХі }\end{array}$ & $\begin{array}{c}\text { Относительная } \\
\text { важность, ОВі }\end{array}$ & $\begin{array}{c}\text { Инвестици- } \\
\text { онные цели } \\
\text { клиники }\end{array}$ & Конкурент & $\begin{array}{l}\text { Желаемый } \\
\text { уровень, уі }\end{array}$ \\
\hline 1 & Проф. знания & 0.15 & $\begin{array}{c}\text { Повысить до } \\
\text { уровня } 5 \text { (+0.15) }\end{array}$ & 5 & 5 \\
\hline 2 & Опыт работы & 0.09 & $\begin{array}{c}\text { Повысить до } \\
\text { уровня } 4(+0.09)\end{array}$ & 2 & 4 \\
\hline 3 & Интеллект & 0.17 & 3 & 3 & 4 \\
\hline 4 & Качества личности & 0.14 & 4 & 3 & 3 \\
\hline 5 & Здоровье & 0.17 & $\begin{array}{c}\text { Повысить до } \\
\text { уровня } 5(+0.34)\end{array}$ & 4 & 3 \\
\hline 6 & Соц.-сихологические качества & 0.11 & 4 & 4 & 4 \\
\hline 7 & Уровень социализации & 0.19 & 3 & 4 & 5 \\
\hline \multicolumn{3}{|c|}{ Прогноз уровня качества человеческого капитала } & $\begin{array}{c}4.04 \\
\text { (высокий) }\end{array}$ & $\begin{array}{c}3.74 \\
\text { (высокий) }\end{array}$ & $\begin{array}{c}4 \\
\text { (высокий) }\end{array}$ \\
\hline
\end{tabular}


Таблица 5. Целевая программа развития конкурентоспособности человеческого капитала.

\begin{tabular}{|c|c|c|c|c|c|}
\hline № & Мероприятие & Объем, у.е. & Цель & Срок & $\begin{array}{c}\text { Ожидаемый } \\
\text { результат }\end{array}$ \\
\hline 1 & Повышение квалификации & 9000 & $\begin{array}{c}\text { Повысить уровень } \\
\text { на } 0.15\end{array}$ & 1 год & 5 \\
\hline 2 & $\begin{array}{c}\text { Профессиональная переподго- } \\
\text { товка (новая практика) }\end{array}$ & 3000 & $\begin{array}{c}\text { Повысить уровень } \\
\text { на } 0.09\end{array}$ & 2 мес. & 4 \\
\hline 3 & Повышение уровня здоровья & 1200 & $\begin{array}{c}\text { Повысить уровень } \\
\text { на } 0.34\end{array}$ & 0,5 года & 5 \\
\hline \multicolumn{3}{|c|}{ Прогноз уровня качества человеческого капитала } & 4.04 & 1 год & $\begin{array}{l}\text { Конкуренто- } \\
\text { способность. }\end{array}$ \\
\hline
\end{tabular}

с завершением третьего мероприятия. Ее значение составляет 750 у.е./мес.

Таким образом, инвестиционная программа состоит из трех этапов разной продолжительности. На первом этапе суммарное финансирование равно 4900 у.е. (37,1\%). На втором этапе оно равно 3800 у.е. (28,8\%), а на третьем - 4500 у.е. (34,1\%). Проведенный расчет позволяет сделать вывод, что наиболее сложным и капиталоемким является первый этап целевой программы, он требует эффективного управления тремя мероприятиями одновременно. Третий этап позволяет сфокусировать управление на первом мероприятии, то есть имеет минимальный риск успешного завершения.

В иллюстративном примере предполагалось, что практическая переподготовка персонала допускает совмещение с теоретической. Применение параллельной структуры мероприятий позволило максимально сократить срок выполнения ЦП, но, соответственно, привело к увеличению интенсивности инвестирования на первом этапе. В условиях ограничений на интенсивность инвестиций, следует отказаться от проекта «параллельной» структуры. В этом случае срок проекта возрастет, то есть отдалит срок достижения целевого уровня конкурентоспособности. Применение проекта «последовательной» структуры позволяет максимально снизить интенсивность инвестиционной потребности, но существенно увеличивает срок его выполнения. В иллюстративном примере он возрастает более чем в полтора раза. Рассмотренный пример основан на детерминированной модели инвестиционной программы в условиях полной информационной определенности.

На практике имеют место условия частичной или полной информационной неопределенности о поведении внешней среды, которая на конкурентном рынке медицинских услуг имеет реактивный характер. В условиях частичной неопределенности предполагается, что вероятностные характеристики внешней среды известны. Расчету подлежит средний прогнозируемый уровень конкурентоспособности человеческого капитала. Как правило, в задаче используются так называемые субъективные вероятности стратегий внешней среды, получаемые методом экспертных оценок. При отсутствии вероятностных характеристик реактивных стратегий внешней среды (конкурентных услуг) необходима матричная модель инвестиционного прогнозирования процесса развития человеческого капитала.

В основе задачи оптимизации находится матрица конкурентоспособности, элементами которой являются прогнозные значения уровня конкурентоспособности человеческого капитала, оцениваемые для каждой конкретной стратегии его развития и определенной реактивной конкурентной стратегии заданного вида. В качестве критерия оптимизации в этом случае, чаще всего, применяется принцип минимакса, основанный на предположении о наихудших реактивных стратегиях конкурента и стремлении в этих условиях получить максимальный результат, то есть максимальный средний уровень конкурентоспособности человеческого капитала. Оптимальным решением в матричной модели является так называемая смешанная стратегия развития. Ей соответствует оптимальная пропорция инвестирования денежных средств в исходные альтернативные стратегии развития конкурентоспособности человеческого капитала. Исходный набор подобных стратегий должен обладать свойством эффективности, то есть каждая из стратегий не должна уступать всем остальным при заданном наборе конкурентных ситуаций.

Таким образом, можно сделать вывод, что в условиях перспективной неопределенности поведения реактивной внешней среды, наилучшей 
является комбинированная стратегия развития конкурентоспособности человеческого капитала, то есть одновременно следует реализовать несколько эффективных инвестиционных проектов при условии оптимальной пропорции их финансирования. В этом случае клиника может гарантировать себе в перспективе максимальный средний уровень конкурентоспособности «своего» человеческого капитала и, соответственно, конкурентное превосходство на рынке медицинских услуг. Необходимым условием сохранения конкурентоспособности человеческого капитала на долгий срок является применение метода скользящего планирования, то есть ежегодной коррекции программы с учетом новой информации о внешней и внутренней среде клиники. В течение года могут произойти существенные изменения на рынке медицинских ус- луг, имеющие реактивный характер: конкуренты могут перейти на более эффективные стратегии развития конкурентоспособности, а потребители - внести изменения в систему своих предпочтений относительно наилучшего соотношения ценовых и неценовых характеристик медицинских услуг. За год существенно изменяется состояние мировой экономики, в настоящее время приобретающей тенденцию к стагнации. В силу высокого уровня интеграции экономики РФ в мировую, имеет место факт доминирующего влияния внешней среды на национальную экономику, которое проявляется в обострении конкурентной борьбы и, соответственно, системной актуализации проблемы обеспечения стратегической конкурентоспособности фирм на рынках товаров и услуг, техники и технологий.

\section{Библиографический список}

1. Герасимова С.В. Концепция человеческого капитала в развитии конкурентоспособности медицинских услуг. Экономические науки № 9(178), 2019. С. 25-28.

2. Герасимова С.В. Современные проблемы развития стратегической конкурентоспособности на рынке услуг. Экономические науки № 1(146), 2017. С 11-14.

3. Гуськова М.Ф., Стерликов П. Ф., Стерликов Ф. Ф. Экономическая жизнь людей // Экономические науки № 2 (147), 2017. C. 11-15.

4. Гуськова М.Ф., Стерликов П. Ф., Стерликов Ф. Ф. К вопросу оценки бизнеса // Экономические науки № 9(142), 2016, С. 30-36.

5. Чарльз И. Джонс, Дитрих Волларт Введение в теорию экономического роста. - М.: Издательский дом «Дело» РАНХиГС, 2018. 